\title{
Can chronic postsurgical pain be prevented by using regional block?
}

\author{
Young-Kwon Ko \\ Department of Anesthesiology and Pain Medicine, Chungnam National University College of Medicine, Daejeon, \\ Korea
}

After undergoing a common surgery, $10 \%-50 \%$ of patients complain of acute pain, among whom $2 \%-10 \%$ patients experience transition to severe chronic pain [1]. This persistent postsurgical pain is a clinical problem, as its duration is long. Chronic postsurgical pain (CPSP) is "newly presenting pain after surgery" or "a different type of pain on the operation site" lasting for more than 3 months. Pain with a probable cause, such as cancer or infection, is excluded [2].

There are various risk factors for CPSP with respect to the patient and surgery type. However, the exact cause of CPSP has not been identified. Some studies reported that the surgery type, extent of tissue damage, and neural damage affect CPSP.

According to Sasso et al. [3], 43\% patients suffered pain for 3 months among the 280 patients who underwent iliac crest bone grafting, and $33 \%$ patients complained of pain even for a year. Transversalis fascia plane (TFP) block could be effective in controlling acute postoperative pain after iliac crest bone graft harvesting, as reported by Nicholas et al. [4], in the Korean Journal of Anesthesiology. Only 1 of the 23 patients reported of moderately severe pain for 12 months after the TFP block. This result shows a marked difference from previous studies on the occurrence of CPSP. Therefore, TFP block and effective use of analgesics are expected to provide better outcomes for CPSP, although further studies are needed. Since the risk of CPSP correlates with the postoperative pain degree, active control of postoperative pain is important.

As a pain control method, ultrasound-guided regional block is effective not only for anesthesia but also pain control after surgery. Moreover, regional anesthesia could prevent CPSP associated with most surgeries [5]. However, additional studies are required because controversies exist. In conclusion, since postoperative CPSP has high incidence and severity, anesthesiologists should actively engage in research focused on prevention.

\section{Conflicts of Interest}

No potential conflict of interest relevant to this article was reported.

\section{References}

1. Kehlet H, Jensen TS, Woolf CJ. Persistent postsurgical pain: risk factors and prevention. Lancet 2006; 367: 1618-25.

2. Werner MU, Kongsgaard UE. Defining persistent post-surgical pain: is an update required? Br J Anaesth 2014; 113: 1-4.

3. Sasso RC, LeHuec JC, Shaffrey C. Iliac crest bone graft donor site pain after anterior lumbar interbody fusion: a prospective patient satisfaction outcome assessment. J Spinal Disord Tech 2005; 18 Suppl: S77-81.

4. Black ND, Malhas L, Jin R, Bhatia A, Chan VW, Chin KJ. The analgesic efficacy of the transversalis fascia plane (TFP) block in iliac crest

Corresponding author: Young-Kwon Ko, M.D., Ph.D.

Department of Anesthesiology and Pain Medicine, Chungnam National University College of Medicine, 282 Munhwa-ro, Jung-gu, Daejeon 35015 , Korea

Tel: +82-42-280-7841, Fax: +82-42-280-7968, Email: annn8432@gmail.com

ORCID: https://orcid.org/0000-0002-0178-6346

Received: June 26, 2019. Accepted: June 26, 2019.

Korean J Anesthesiol 2019 August 72(4): 295-296

https://doi.org/10.4097/kja.19279

(c) This is an open-access article distributed under the terms of the Creative Commons Attribution Non-Commercial License (http://creativecommons.org/ licenses/by-nc/4.0/), which permits unrestricted non-commercial use, distribution, and reproduction in any medium, provided the original work is properly cited. 
bone graft harvesting: a randomized controlled trial. Korean J Anesthesiol 2019; 72: 336-43.

5. Buvanendran A. Multimodal analgesia for perioperative pain management. Paper presented at: IARS 2011 review course lectures. 2011 Annual Meeting of the International Anesthesia Research Society; 2011 May 21-24; Washington DC, Vancouver, Canada. 